EGU2020-7888

https://doi.org/10.5194/egusphere-egu2020-7888

EGU General Assembly 2020

(c) Author(s) 2021. This work is distributed under

the Creative Commons Attribution 4.0 License.

\title{
Research challenges on gully erosion control in EU and China
}

\author{
Jose Alfonso Gomez ${ }^{1}$, Guangju Zhao ${ }^{2}$, Honghu Liu ${ }^{3}$, Yu Yang ${ }^{4}$, Javier Lopez ${ }^{5}$, and Yun Xie \\ ${ }^{1}$ Inst.for Sustainable Agriculture. CSIC., Agronomy, Cordoba, Spain (joseagomez@ias.csic.es) \\ ${ }^{2}$ State Key Laboratory of Soil Erosion and Dryland Farming on the Loess Plateau, Northwest A\&F University, Yangling, China \\ (gjzhao@ms.iswc.ac.cn)) \\ ${ }^{3}$ Changjiang River Scientific Research Institute (CRSRI), Wuhan, China (liuhh@mail.crsri.cn) \\ ${ }^{4}$ Department of Sediment Research, China Institute of Water Resources and Hydropower Research \\ (theodoreyy@gmail.com) \\ ${ }^{5}$ Department of Engineering, Public University of Navarre (UPNA), Spain (jjlr@unavarra.es)
}

Gully erosion is a soil degradation process widely present across the world. Permanent gully erosion has usually soil erosion rates one order of magnitude higher than hillslope water erosion in conventional agriculture, e.g. 2.1 vs $0.6 \mathrm{~mm}_{\text {year }}{ }^{-1}$ (Castillo and Gómez, 2016). It remains a major process of soil degradation worldwide.

This work attempts to investigate recent trends of published research on gully erosion in relation to gully erosion control since 2000. A review in Web of Science (core collection, 2000-19 by title) reported 401 documents, produced mainly in the European Union (52.1\%), China (22.7\%), USA (16.0\%) and Australia (8.7\%). Approximately $17 \%$ of all these articles covered restoration or control of gully erosion as their main topic. When screened most of these 68 articles deal with specific situations and techniques with a limited number devoted to a comparative review of effectiveness of different techniques, one of the few exceptions was Liu et al. (2019a). To provide perspective, there were a similar proportion of articles devoted to the study of gully erosion processes, a and a much larger number of articles devoted to the description of gully development and erosion rates in specific situations. It is apparent that the subject of gully erosion control is not a dominant one in the scientific indexed literature. This review was complemented with an analysis in WOCAT (WOCAT, 2019), a comprehensive international databases of soil conservation technologies. It showed with 27 entries of gully erosion restoration techniques over a total of 1098 descriptions (2.5\% approximately). This might be explained, partially, because most of the information on gully erosion control appears in documents outside scientific, or technical, international databases, many times in local languages. Overall, two of the major barriers frequently noted by stakeholders, particularly farmers, for effective gully erosion control, their high costs and the complexity of controlling expansion of very large gullies (e.g. Liu et al.2019b) are not major major subjects in the international scientific literature on gullies in the last decades. 
It is apparent that there is the need for a more comprehensive comparative analysis of the effectiveness and cost of different strategies of gully erosion control techniques, particularly oriented to reduce the investment cost of their implementation, especially in very large gullies where compex slope instability processes might play a dominant role. This communication presents a comprehensive analysis on the available information on international scientific literature on gully erosion research to suggest key lines and strategies for future research.

\section{References}

Castillo, C., Gómez, J.A. 2016 A century of gully erosion research: Urgency, complexity and study approaches Earth-Science Reviews 160: 300-319

Liu, X., et al. 2019a. Gully Erosion Control Practices in Northeast China: A Review. Sustainability 11: 5065, doi:10.3390/su11185065

Liu, H., et al. 2019b. Using 3D scanner to study gully evolution and its hydrological analysis in the deep weathering of southern China. Catena 183. https://doi.org/10.1016/j.catena.2019.104218

WOCAT. 2020. World Overview of Conservation Approaches and Technologies. https://www.wocat.net/en/ 